\title{
TiN-Coating Effects on Stainless Steel Tribological Behavior Under Dry and Lubricated Conditions
}

\author{
Liqiang Zhang, Huisheng Yang, Xiaolu Pang, Kewei Gao, Hai T. Tran, and Alex A. Volinsky
}

\author{
(Submitted August 11, 2013; in revised form December 31, 2013; published online February 20, 2014)
}

\begin{abstract}
The tribological properties of magnetron sputtered titanium nitride coating on 316 $\mathrm{L}$ steel, sliding against $\mathrm{Si}_{3} \mathrm{~N}_{4}$ ceramic ball under dry friction and synthetic perspiration lubrication, were investigated. The morphology of the worn surface and the elemental composition of the wear debris were examined by scanning electron microscopy and energy dispersive spectroscopy. TiN coatings and 316L stainless steel had better tribological properties under synthetic perspiration lubrication than under dry friction. Among the three tested materials (316L, 1.6 and $2.4 \mu \mathrm{m}$ TiN coatings), $2.4 \mu \mathrm{m}$ TiN coating exhibits the best wear resistance. The difference in wear damage of the three materials is essentially due to the wear mechanisms. For the TiN coating, the damage is attributed to abrasive wear under synthetic perspiration lubrication and the complex interactive mechanisms, including abrasive and adhesive wear, along with plastic deformation, under dry friction.
\end{abstract}

Keywords dry friction, synthetic perspiration lubrication and wear mechanism, titanium nitride coating

\section{Introduction}

Titanium nitride (TiN) coatings deposited by physical vapor deposition (PVD) on cutting tools and other material surfaces susceptible to wear help extending the life and the range of operating conditions (Ref 1). Several studies of TiN and similar hard coatings wear have highlighted their advantages over uncoated tools (Ref 2-4). TiN coatings wear can change dramatically with adjusting parameters, such as contact load, sliding speed, contact geometry, and humidity. Complexities associated with attempting to characterize and model wear in different modes of damage that occur during machining and cutting in dry sliding operations were also revealed (Ref 1). In (Ref 1) three wear regimes were identified. The investigation characterized transitions among different wear mechanisms, depending on the load, sliding distance, and temperature of the pin. The effects of humidity and microstructure of the tribolayers in TiN coatings have been investigated in (Ref 2). Reference 3 studied fretting of TiN and $\mathrm{MoS}_{2}$ coatings on 1045 steel and showed that the fretting wear mechanism of TiN coating is particle detachment through propagation and fracture of fine microcracks on the surface. Reference 4 studied the performance of $\mathrm{TiN}, \mathrm{CrN}$, and $\mathrm{WC} / \mathrm{C}$ coatings on steel substrates and found that the load was an important factor in the wear life variation, although other factors, such as surface roughness and

Liqiang Zhang, Huisheng Yang, Xiaolu Pang, and Kewei Gao, Department of Materials Physics and Chemistry, University of Science and Technology Beijing, Beijing 100083, China; and Hai T. Tran and Alex A. Volinsky, Department of Mechanical Engineering, University of South Florida, Tampa, FL 33620. Contact e-mail: pangxl@mater.ustb. edu.cn. coating thickness, were also significant. Additionally, surface morphology significantly affects wear and friction under sliding conditions (Ref 5). Also, (Ref 6) investigated the relationship between the hardness and tribological properties of nanolayered TiN/TaN multilayer coatings. It indicated that the wear volume increased with decreasing hardness and exhibited a linear relationship with the inverse of the hardness.

In this paper, the wear behavior of TiN-coated $316 \mathrm{~L}$ stainless steel substrates sliding against silicon nitride $\left(\mathrm{Si}_{3} \mathrm{~N}_{4}\right)$ ceramic ball under dry friction and synthetic perspirationlubricated conditions was studied. $\mathrm{A} \mathrm{Si}_{3} \mathrm{~N}_{4}$ ball was selected as the counterpart of TiN and $316 \mathrm{~L}$ stainless steel to simulate the wear of artificial joints consisting of stainless steel and ceramic head. TiN coatings were deposited on $316 \mathrm{~L}$ stainless steel by reactive radio frequency (RF) pulsed magnetron sputter deposition in an industrial PVD system.

\section{Experimental Details}

\subsection{Materials}

The substrate was $316 \mathrm{~L}$ stainless steel, machined into coupons $20 \mathrm{~mm}$ in diameter and $2.5-\mathrm{mm}$ thick, ground to an average surface roughness of $R_{\mathrm{a}}=0.02 \mu \mathrm{m}$ (shown in Fig. 1a). The chemical composition is listed in Table 1 . TiN coatings were deposited on $316 \mathrm{~L}$ stainless steel substrates by reactive sputtering at $300{ }^{\circ} \mathrm{C}$. The growing coating was ion bombarded by applying a substrate bias voltage of $-80 \mathrm{~V}$, and the target power was $300 \mathrm{~W}$. The chamber pressure during the sputtering process was $0.25 \mathrm{~Pa}$. In order to get a stronger adhesion between the $316 \mathrm{~L}$ steel stainless substrate and the TiN coating, a thinner Ti film was deposited before $\mathrm{N}_{2}$ was introduced into the chamber. The thickness of deposited TiN coatings was 1.6 and $2.4 \mu \mathrm{m}$.

The balls with $3.75-\mathrm{mm}$ diameter were made from silicon nitride. For comparison, some uncoated 316L steel stainless disk specimens were also tested. The average hardness and 
fracture toughness values for $316 \mathrm{~L}$ steel substrates and TiN coatings are listed in Table 2 . The micro-hardness values measured by nanoindentation were obtained by measuring five different points to calculate an average value. The loading rate was $10 \mathrm{~nm} / \mathrm{s}$, and the loading depth was $500 \mathrm{~nm}$. The fracture toughness of TiN coatings was estimated using the radial cracking indentation method (Ref 7) by measuring the length of radial cracks. The radial cracks in TiN coating were introduced by indenting it with a sharp Vickers indenter, and the relationship between the fracture toughness and the length of radial cracks was established (Ref 8,9$)$.

\subsection{Wear Tests}

The sliding wear tests were performed in a ball-on-flat reciprocating wear tester, which conforms to the ASTM G133, and the two materials (bare 316L stainless steel and TiN coated $316 \mathrm{~L}$ stainless steel) were rubbed against a silicon nitride ball (3.75-mm diameter) under dry friction and synthetic perspiration-lubricated conditions at an ambient temperature of $25^{\circ} \mathrm{C}$. Components of the synthetic perspiration are sodium bicarbonate $\left(4.2 \times 10^{-3} \mathrm{~kg} / \mathrm{L}\right)$, sodium chloride $\left(0.5 \times 10^{-3} \mathrm{~kg} / \mathrm{L}\right)$, and potassium carbonate $\left(0.2 \times 10^{-3} \mathrm{~kg} / \mathrm{L}\right)$, and the $\mathrm{pH}$ of the synthetic perspiration is 8.8 . The reciprocator is controlled by a function generator. The following experimental parameters were selected: $5 \mathrm{~N}$ normal load, $15-\mathrm{mm}$ slip amplitude, $60-\mathrm{Hz}$ frequency, and 40-min testing time. The specimens were cleaned in an ultrasonic alcohol bath before testing. Figure 2 shows a schematic of the ball-on-flat testing configuration.

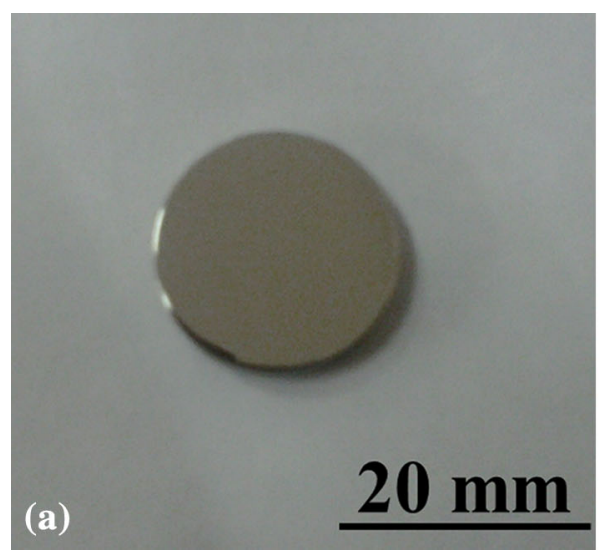

During the experiments, the variation of friction coefficient with the number of cycles was recorded. Veeco Dektak 150 stylus profilometer was used to determine the depth profiles and cross-sectional areas of the wear tracks. Based on the wear track diameter and depth profiles at several locations, the coating volume removed during testing was obtained to evaluate the coating wear resistance. The friction tests were repeated three times for each condition. The wear scar morphology was examined by scanning electron microscopy (SEM), and the chemical composition was obtained from the energy dispersive spectroscopy (EDS).

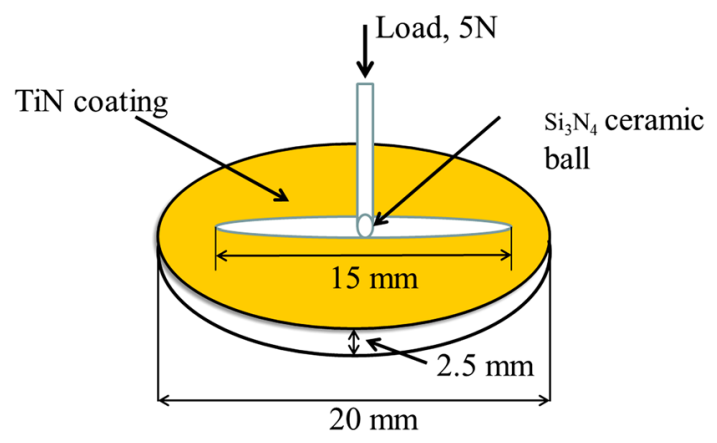

Fig. 2 Schematic showing the ball-on-flat wear test configuration

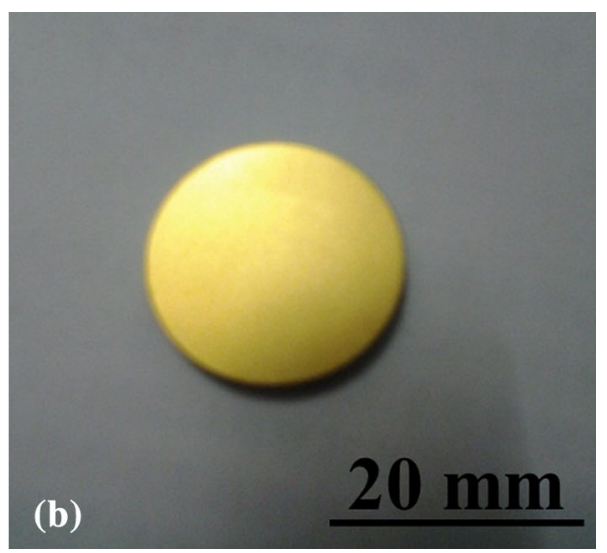

Fig. 1 (a) 316L stainless steel substrate; (b) TiN coating deposited on the 316L stainless steel substrate

Table 1 Nominal chemical composition of 316L stainless steel

\begin{tabular}{lcccccccccc}
\hline Material & $\mathbf{C}$ & $\mathbf{S i}$ & $\mathbf{F e}$ & $\mathbf{M n}$ & $\mathbf{N i}$ & $\mathbf{C r}$ & Mo & V & P & Co \\
\hline $316 \mathrm{~L}$ & $0.019 \%$ & $0.71 \%$ & Bal. & $0.97 \%$ & $12.08 \%$ & $17.43 \%$ & $2.15 \%$ & $0.027 \%$ & $0.011 \%$ & $0.027 \%$ \\
\hline
\end{tabular}

Table 2 Mechanical properties of the specimens

\begin{tabular}{lccc}
\hline Substrate materials & Coating & Average hardness (error bars), GPa & Fracture toughness, MPa m $^{\mathbf{1} \mathbf{2}}$ \\
\hline $316 \mathrm{~L}$ & $\ldots$ & $5(0.8)$ & $\ldots$ \\
$316 \mathrm{~L}$ & $\operatorname{TiN}(1.60 \mu \mathrm{m})$ & $26(1.8)$ & 0.69 \\
$316 \mathrm{~L}$ & $\operatorname{TiN}(2.40 \mu \mathrm{m})$ & $20(1.5)$ & 0.80 \\
\hline
\end{tabular}




\section{Results}

\subsection{Friction Coefficient}

The friction coefficient of the $316 \mathrm{~L}$ stainless steel under dry friction and synthetic perspiration-lubricated conditions is shown in Fig. 3. It can be seen that the friction coefficient of the $316 \mathrm{~L}$ stainless steel under dry friction is always higher than under synthetic perspiration. At the beginning of the test, the friction coefficient of the $316 \mathrm{~L}$ stainless steel under dry friction increased rapidly to the largest 0.75 value before $768 \mathrm{~s}$. After $800 \mathrm{~s}$, it decreased from 0.75 to 0.65 with a small fluctuation and maintained the 0.65 level during the following cycles, until the test was finished. The friction coefficient of the bare $316 \mathrm{~L}$ stainless steel under synthetic lubricated conditions increased rapidly at the beginning and reached the largest value of 0.46 after $450 \mathrm{~s}$. During the following cycles, it showed a large decrease from 0.46 to 0.27 and then increased rapidly to 0.44 before $1000 \mathrm{~s}$. In the following cycles, it remained at 0.44 , until the test was finished.

Comparing the friction coefficient of bare $316 \mathrm{~L}$ stainless steel under dry friction and synthetic lubrication, it was found that the friction coefficient increased rapidly at the beginning of the test; thus, it was called the running-in stage. Later, the friction coefficient remained relatively stable, called the steady stage, until the test was finished. Reference 6 showed that the coefficient of friction can be approximately divided into two stages, i.e., the running-in stage and the steady stage. The coefficient of friction was low at the running-in stage and gradually increased to a steady value at the steady stage. This conclusion agrees well with the findings in this paper.

In a similar way, the steady state friction coefficients for different thickness TiN (1.60 and $2.4 \mu \mathrm{m})$ coated on the $316 \mathrm{~L}$ stainless steel under dry friction and synthetic lubrication were investigated, shown in Fig. 4. As seen in Fig. 4, the friction coefficient of the three materials (bare $316 \mathrm{~L}, 1.6$ and $2.4 \mu \mathrm{m}$ TiN coatings) under dry friction was always higher than under synthetic perspiration. Under dry friction, 316L stainless steel gave the highest friction coefficient among the three tested materials and reached 0.65 , while the friction coefficients of TiN coatings $(1.6$ and $2.4 \mu \mathrm{m})$ were close to 0.6 . Under synthetic perspiration-lubricated conditions, the $1.6 \mu \mathrm{m}$ TiN coating gave the highest friction coefficient of 0.49 ; however, the $2.4 \mu \mathrm{m}$ TiN coating gave the lowest friction coefficient of 0.3 .

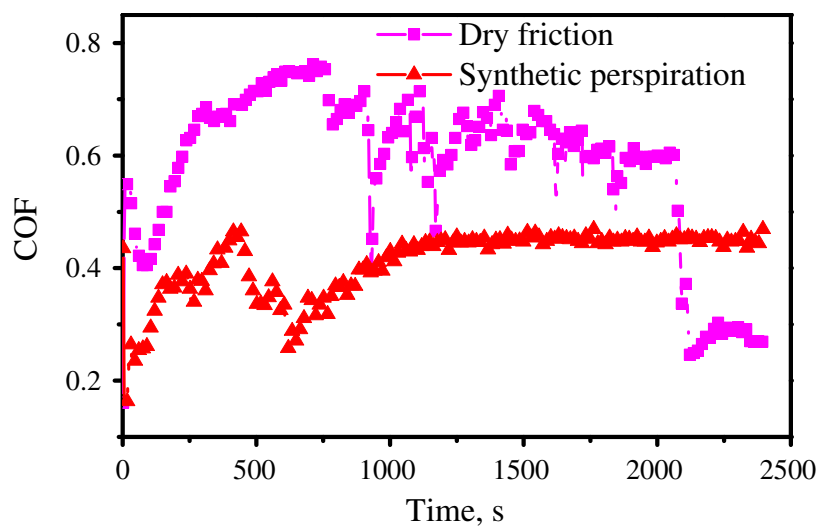

Fig. 3 The friction coefficient of the 316L stainless steel under dry friction and synthetic perspiration-lubricated friction

\subsection{Wear Rate}

These tests caused wear scars on the flat specimens with measurable grooves. The wear depth of each groove was measured using Veeco Dektak 150 stylus profilometer. Since the depth varied along the length of the groove, several depth measurements (transverse to the length of the groove) were taken. The average depth was taken from these measurements. The volume of an ideal groove can be calculated using the following approximation (Ref 10,11$)$ :

$V=S \cdot l$,

$R=\frac{V}{P L}$.

Here $S$ is the transverse area; $l$ is the slip amplitude; $R$ is the wear rate; $P$ is the applied load; and $L$ is the sliding distance. $S$ was calculated using the software package Origin 8.5. The wear rates $(R)$ were obtained from the scar profiles, which determined the size of the scar (depth, width and length). The scar profile of the $1.6 \mu \mathrm{m}$ TiN coating under synthetic perspiration-lubricated friction is shown in Fig. 5.

The specific wear rates of the three materials $(316 \mathrm{~L}, 1.6$ and $2.4 \mu \mathrm{m}$ TiN coatings) under dry friction and synthetic perspiration-lubricated conditions are shown in Fig. 6. In the case of dry friction, the $1.6 \mu \mathrm{m}$ TiN coating exhibited the highest wear,

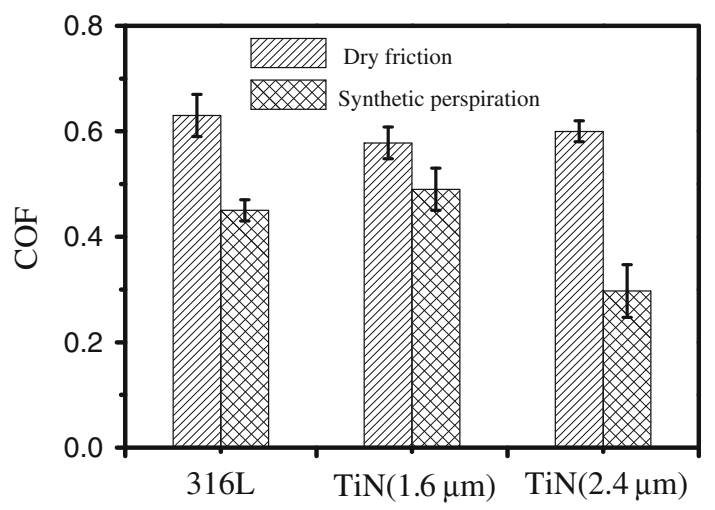

Fig. 4 Steady state friction coefficient of the three materials (316L, $1.6 \mu \mathrm{m} \mathrm{TiN}$ and $2.4 \mu \mathrm{m}$ TiN coating) under dry friction and synthetic perspiration-lubricated friction

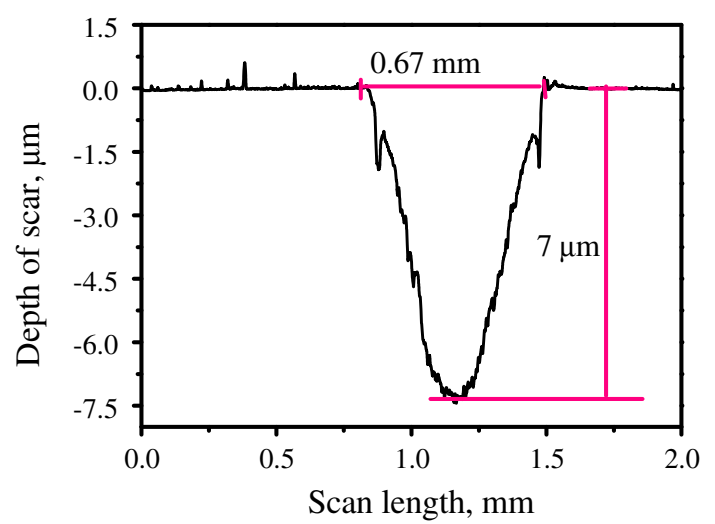

Fig. 5 The scar profiles of the $1.6 \mu \mathrm{m}$ TiN coating under synthetic perspiration-lubricated friction 


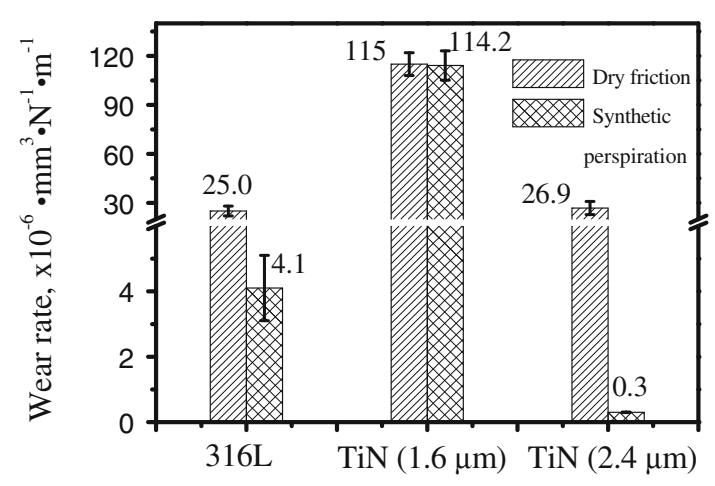

Fig. 6 Wear rates of the three materials $(316 \mathrm{~L}, 1.6 \mu \mathrm{m} \mathrm{TiN}$ and $2.4 \mu \mathrm{m}$ TiN coating) under dry friction and synthetic perspirationlubricated friction

followed by the $316 \mathrm{~L}$ stainless steel, and finally, the $2.4 \mu \mathrm{m}$ TiN coating. The same was observed under synthetic perspiration-lubricated conditions. It is obvious that the wear rates of the three materials $(316 \mathrm{~L}, 1.6$ and $2.4 \mu \mathrm{m}$ TiN coatings) under dry friction were always higher than under synthetic perspiration-lubricated conditions, and the wear rate of the $2.4 \mu \mathrm{m}$ TiN coating was more than twelve times lower than that of the bare 316L stainless steel under synthetic perspiration-lubricated conditions.

In conclusion, under synthetic perspiration-lubricated conditions, $2.4 \mu \mathrm{m}$ TiN coating shows the lowest wear damage and the same wear level as bare $316 \mathrm{~L}$ stainless steel under dry friction; therefore, it exhibits the best wear resistance. On the contrary, the $1.6 \mu \mathrm{m}$ TiN seriously degrades the wear resistance of the $316 \mathrm{~L}$ stainless steel.

3.2.1 Microscopic Analysis. The wear scar morphology of the three materials (316L, 1.6 and $2.4 \mu \mathrm{m}$ TiN coatings) under dry friction is shown in Fig. 7. In the case of $316 \mathrm{~L}$ stainless steel, it is clear that there is evidence of pitting and adhesive wear (Fig. 7a). The pitting and adhesive wear is obviously seen in Fig. 7(b), and there is TiN-coating delamination present at the wear scar edge. The delamination is not observed for the $2.4 \mu \mathrm{m}$ TiN coating shown, but there are more parallel cracks at the wear scar edge (Fig. $7 \mathrm{c})$, and most of the transferred debris particles are raised. In addition, it is seen in Fig. 7(b) that the wear damage is of the plow character.

The chemical composition obtained from the EDS profiles is listed in Table 3 for the three materials under dry friction. It is clearly seen that silicon mass ratio in the wear scar is higher than in the $316 \mathrm{~L}$ stainless steel substrate $(0.71 \mathrm{wt} . \%$, shown in Table 1). This indicates that some $\mathrm{Si}$ from the $\mathrm{Si}_{3} \mathrm{~N}_{4}$ ceramic ball transferred to the contact wear interface between the $\mathrm{Si}_{3} \mathrm{~N}_{4}$ ball and the $316 \mathrm{~L}$ stainless steel. For the $1.6 \mu \mathrm{m}$ TiN and $2.4 \mu \mathrm{m}$ TiN coatings, silicon was also observed in the wear interface between the $\mathrm{Si}_{3} \mathrm{~N}_{4}$ ball and the TiN coatings, indicating that $\mathrm{Si}$ also transferred during sliding between the $\mathrm{Si}_{3} \mathrm{~N}_{4}$ ceramic ball and the TiN coatings. This result agrees with the SEM surface micrographs in Fig. 7b. For the three tested materials, the large mass ratio of oxygen and iron was observed in the wear scar. This indicates that the materials were oxidized and formed iron oxides (e.g., $\mathrm{Fe}_{2} \mathrm{O}_{3}$ ) and titanium oxides (e.g., $\left.\mathrm{TiO}_{2}\right)($ Ref $1,2,12,13)$. The two TiN coatings $(1.6$ and $2.4 \mu \mathrm{m}$ TiN) had been traversed in the direction perpendicular to the surface grinding corrugations and exposed the $316 \mathrm{~L}$ stainless steel substrate.
Under synthetic perspiration-lubricated friction, the wear scar morphologies for the three materials (316L, 1.6 and $2.4 \mu \mathrm{m}$ TiN coatings) are shown in Fig. 8. It is clearly seen that the wear damage of the $316 \mathrm{~L}$ stainless steel and the $1.6 \mu \mathrm{m}$ TiN coating was caused by the plow action (Fig. 8a and b). For the $316 \mathrm{~L}$ stainless steel, there are dark-loose debris particles covering the wear scar edge, seen in Fig. 8(a). EDS analysis (Table 3) reveals that it is rich in $\mathrm{Fe}, \mathrm{O}$ and $\mathrm{Si}$, suggesting the presence of iron and silicon oxides. The $2.4 \mu \mathrm{m}$ TiN coating shows the lowest wear damage (Fig. 8c); the wear scar surface is smooth; and there are no debris particles observed. EDS analysis of the wear scar reveals that it is rich in Ti and N, but not in $\mathrm{O}, \mathrm{Fe}$, or $\mathrm{Si}$. Therefore, $2.4 \mu \mathrm{m} \mathrm{TiN}$ is the best coating, as it exhibits the best wear resistance performance of the three materials tested.

\section{Discussion}

The friction coefficient of the three materials under dry friction was always higher than under synthetic perspiration (Fig. 4). This is essentially due to the action of liquid lubrication. Under synthetic perspiration, liquid at the contact interface can decrease the frictional resistance. Also, during the wear test in synthetic perspiration, the tribo-chemical reactions could easily occur between materials and water (Ref 14, 15). Then, $\mathrm{Si}(\mathrm{OH})_{4}$ and $\mathrm{TiO}_{2}$ could form lubrication films in the contact area. Such lubrication films could decrease the friction coefficient and improve the wear resistance (Ref 16).

The friction coefficient of TiN coatings $(1.6$ and $2.4 \mu \mathrm{m})$ is lower than that of bare $316 \mathrm{~L}$ stainless steel, possibly related to the higher hardness of TiN coatings (Table 1). The relationship between the hardness and the friction coefficient was illustrated in (Ref 6).

Under synthetic perspiration-lubricated conditions, $2.4 \mu \mathrm{m}$ TiN coating shows the lowest wear damage and the same level of wear damage as bare 316L stainless steel under dry friction; therefore, it exhibits the best performance in terms of the wear resistance. On the contrary, the $1.6 \mu \mathrm{m}$ TiN seriously degrades the wear resistance of $316 \mathrm{~L}$ stainless steel. Reference 16 indicated that there were two wear models named as positive wear and negative wear when the sliding wear tests were performed. The positive wear means that the wear debris was removed from the friction surface of tribomaterials immediately, which led to the smoother wear track, while the negative wear means that the wear debris was adhered to the wear track surface, which induced the calculated volume of the wear track. In our $316 \mathrm{~L}$ stainless steel experiment, the stainless steel debris is soft and was adhered to the wear track easily. Thus, its wear model belongs to the negative wear, and the calculated volume of the wear track will be lower than the true value. Contrary, for $1.6 \mu \mathrm{m}$ TiN coating during sliding, more brittle and hard debris particles are formed in the wear scar, which were removed from the friction surface easily, and those debris particles will degrade the TiN coating and the $316 \mathrm{~L}$ substrate more at the later stage of the sliding wear tests. It is clear from Fig. 8(c) that for the $2.4 \mu \mathrm{m}$ TiN coatings, the surface is smooth, and there is no fragile debris particles formed. Thus, the $2.4 \mu \mathrm{m} \mathrm{TiN}$ coatings show the best wear resistance performance. Compared to the $1.6 \mu \mathrm{m}$ TiN coatings, the best wear resistance performance of the $2.4 \mu \mathrm{m}$ TiN coatings is due to the higher fracture toughness and lower hardness value. 

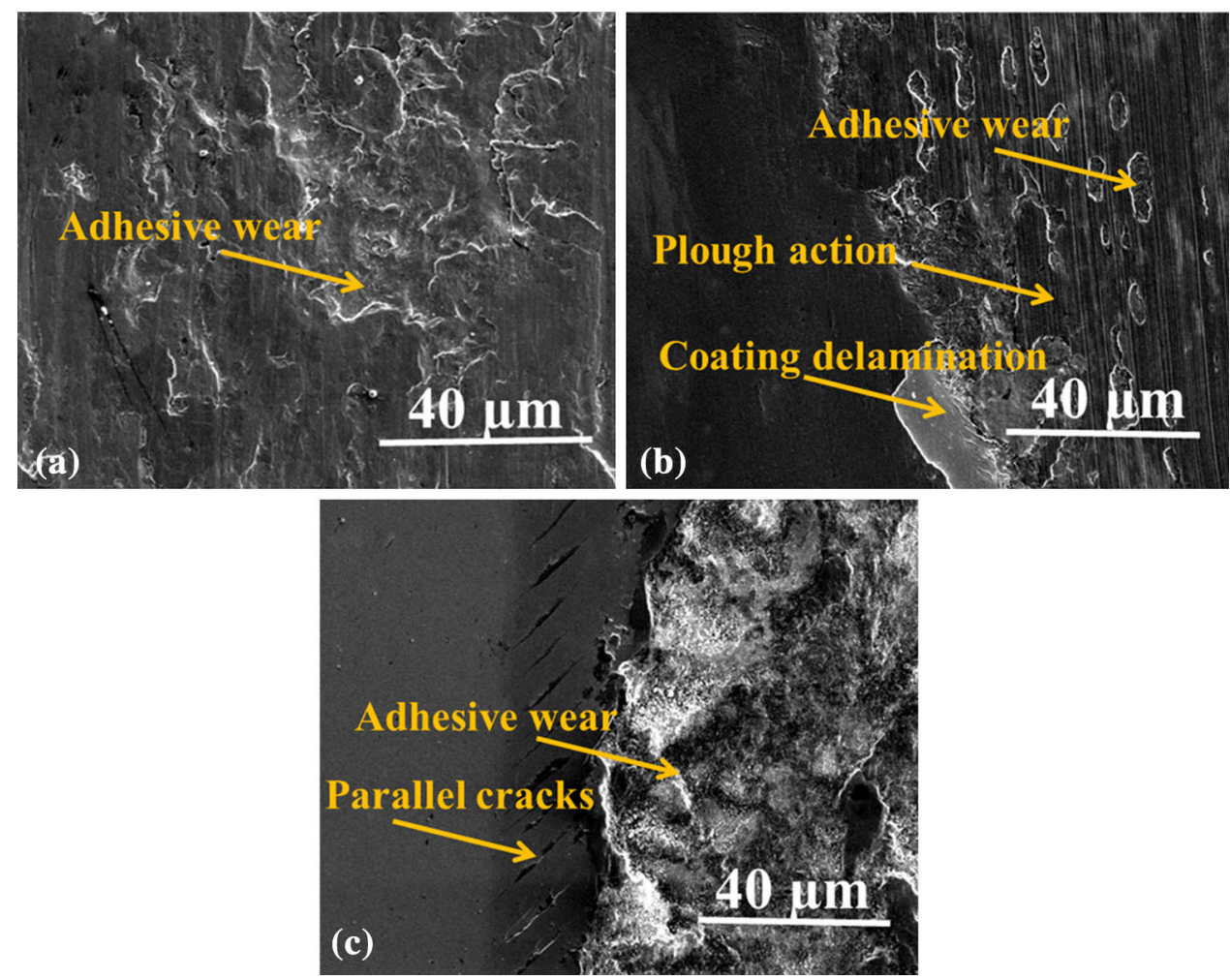

Fig. 7 SEM micrographs of the wear scar in: (a) 316L; (b) $1.6 \mu \mathrm{m} \mathrm{TiN}$; (c) $2.4 \mu \mathrm{m}$ TiN coating under dry friction

Table 3 The mass ratio for various chemical components, varying with the film and substrate materials after the wear tests

\begin{tabular}{|c|c|c|c|c|c|c|c|c|c|c|c|c|c|c|c|}
\hline \multirow[b]{2}{*}{ Environment } & \multirow[b]{2}{*}{ Specimen } & \multicolumn{14}{|c|}{ Mass ratio, wt. $\%$} \\
\hline & & $\mathbf{F e}$ & $\mathbf{O}$ & $\mathbf{S i}$ & $\mathbf{T i}$ & $\mathbf{N}$ & $\mathbf{C r}$ & Mn & $\mathrm{Ni}$ & Mo & $\mathbf{C}$ & $\mathbf{V}$ & $\mathbf{N a}$ & $\mathbf{C l}$ & TI \\
\hline Dry & $316 \mathrm{~L}$ & 57.98 & 7.14 & 3.92 & $\cdots$ & $\cdots$ & 16.82 & 1.73 & 7.70 & 1.81 & 2.90 & $\cdots$ & $\cdots$ & $\cdots$ & $\cdots$ \\
\hline Dry & $\mathrm{TiN}(1.6 \mu \mathrm{m})$ & 41.22 & 11.17 & 0.66 & 8.62 & $\cdots$ & 14.46 & $\cdots$ & 12.96 & $\cdots$ & 8.15 & 0.31 & $\cdots$ & $\cdots$ & 2.45 \\
\hline Dry & $\operatorname{TiN}(2.4 \mu \mathrm{m})$ & 14.56 & 40.07 & 4.98 & 18.68 & $\cdots$ & 3.89 & $\cdots$ & 5 & $\cdots$ & 12.08 & 0.12 & $\cdots$ & $\ldots$ & $\cdots$ \\
\hline Perspiration & $316 \mathrm{~L}$ & 21.57 & 36.33 & 11.38 & $\cdots$ & $\cdots$ & 6.92 & $\cdots$ & 9.43 & $\cdots$ & 12.38 & 0.31 & 1.07 & 0.61 & $\cdots$ \\
\hline Perspiration & $\operatorname{TiN}(1.6 \mu \mathrm{m})$ & 62.82 & 6.06 & $\cdots$ & $\cdots$ & $\cdots$ & 15.08 & 1.22 & 7.75 & $\cdots$ & 7.07 & $\cdots$ & $\cdots$ & $\cdots$ & $\cdots$ \\
\hline Perspiration & $\operatorname{TiN}(2.4 \mu \mathrm{m})$ & $\ldots$ & $\cdots$ & $\cdots$ & 84.21 & 15.79 & $\ldots$ & $\cdots$ & $\cdots$ & $\cdots$ & $\cdots$ & $\cdots$ & $\ldots$ & $\ldots$ & $\cdots$ \\
\hline
\end{tabular}

The wear rates of the three materials $(316 \mathrm{~L}, 1.6$ and $2.4 \mu \mathrm{m}$ TiN coatings) under dry friction were always higher than under synthetic perspiration-lubricated conditions (Fig. 6). The wear damage of the $2.4 \mu \mathrm{m}$ TiN coating was far less than that of the $1.6 \mu \mathrm{m}$ TiN under both friction conditions. This varying wear performance is essentially due to the different wear mechanisms.

Synthetic perspiration decreases the frictional resistance of the friction pair. During this condition, there was more loose wear debris in the wear track edge for the bare $316 \mathrm{~L}$ stainless steel (Fig. 8a). EDS analysis (Table 3) reveals that it is rich in Fe, O and $\mathrm{Si}$, suggesting the presence of softening iron oxides and silicon oxides (Ref 1). This loose wear debris acts as a lubricant and effectively decreases the wear damage. There was lower ductile plow action (higher fracture toughness and lower hardness) observed in Fig. 8(a) also. For the $1.6 \mu \mathrm{m}$ TiN coating, the wear damage was essentially due to brittle spallation (lower fracture toughness and higher hardness); however, there was no wear debris in the wear track (Fig. 8b). EDS analysis (Table 3) of the wear track reveals that the mass ratio of silicon is 0.66 (Table 3), approaching the content of silicon in the $316 \mathrm{~L}$ stainless steel. This suggests that there was no material transfer from the couple to the worn surfaces. The wear damage of the $1.6 \mu \mathrm{m} \mathrm{TiN}$ coating was essentially due to the abrasive wear. For the $2.4 \mu \mathrm{m}$ TiN coating, the wear mechanism was not as clear. The SEM and EDS results indicated that it remains a perfect coating after wear testing and exhibits the best wear resistance performance. The wear resistance of the $2.4 \mu \mathrm{m}$ TiN coating is higher than that of the $1.6 \mu \mathrm{m}$ TiN coating, essentially due to its higher fracture toughness (Table 2). Under the same friction conditions, the relationship among the wear volume, $V$; the hardness of the wear surface, $H$; and the fracture toughness, $K_{\mathrm{c}}$, is:

$V=K \cdot P^{5 / 4} \cdot d^{1 / 2} \cdot K_{\mathrm{c}}^{-3 / 4} \cdot H^{-1 / 2} \cdot L$.

Here, $P$ is the applied load; $L$ is the sliding distance; $d$ and $k$ are constants. 

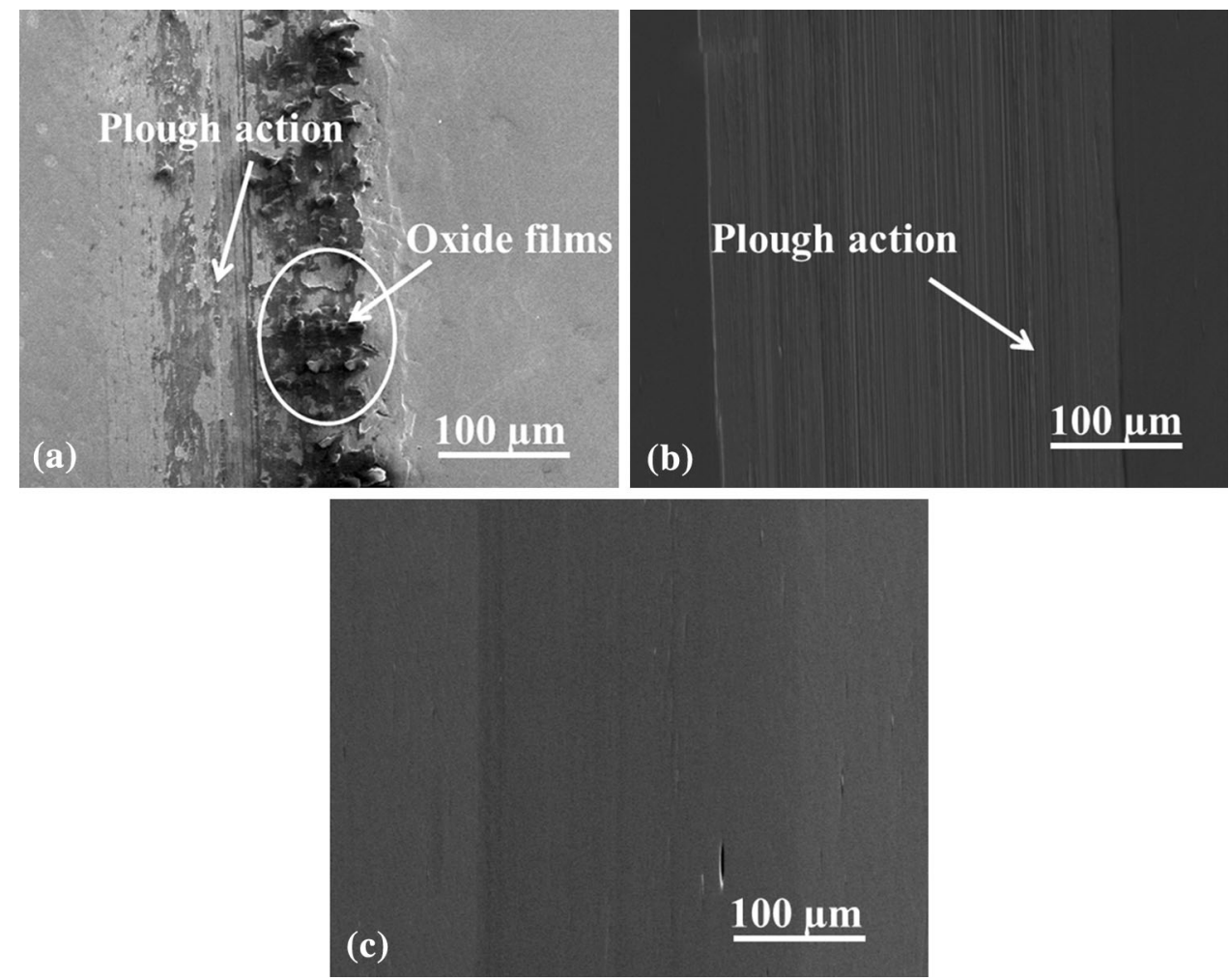

Fig. 8 SEM micrographs of the wear scar in: (a) 316L; (b) $1.6 \mu \mathrm{m} \mathrm{TiN}$; (c) $2.4 \mu \mathrm{m}$ TiN coating under synthetic perspiration-lubricated friction

Under dry friction, the adhesive wear is shown in Fig. 7; however, the form of the wear damage is quite different. For the 316L stainless steel, a large amount of asperities and pitting sites arise around the wear scar (Fig. 7a). There were no asperities observed in the wear track of the $1.6 \mu \mathrm{m}$ TiN coating (Fig. 7b). Smaller size pitting occurred at the wear scar edge. In addition, abrasive wear formed by the plow action in the wear scar and caused coating delamination at the scar edge (Fig. 7b). In the case of the $2.4 \mu \mathrm{m}$ TiN coating, most of the transferred oxidized debris particles are raised above the level of the TiNcoating surface, with TiN plastically deformed around them. In addition, there are more parallel cracks at the wear scar edge (Fig. 7c). Therefore, the wear damage of the $2.4 \mu \mathrm{m}$ TiN coating is caused by complex interactive mechanisms, including abrasive and adhesive wear, along with plastic deformation.

\section{Conclusions}

The friction and wear characteristics of TiN coatings and 316L stainless steel sliding against silicon nitride ball under dry friction and synthetic perspiration-lubricated conditions have been investigated using the ball-on-flat tribometer. The following conclusions can be drawn:

(1) The TiN coatings and 316L stainless steel had better tribological properties under synthetic perspiration-lubricated conditions than under dry friction.

(2) Among the three materials $(316 \mathrm{~L}, 1.6$ and $2.4 \mu \mathrm{m} \mathrm{TiN}$ coating), $2.4 \mu \mathrm{m}$ TiN coating exhibits the best wear resistance performance.
(3) The wear damage of the three materials varies depending on the wear mechanisms. For the TiN coatings, the wear damage is more attributed to the abrasive wear under synthetic perspiration lubrication and the complex interactive mechanisms, including abrasive and adhesive wear, along with plastic deformation under dry friction.

\section{Acknowledgments}

This work was supported by the National Nature Science Foundation of China $(51001013,51271022)$, the Fok Ying Tung Education Foundation (132001), and the Fundamental Research Funds for the Central Universities.

\section{References}

1. S Wilson and AT Alpas, TiN Coating Wear Mechanisms in Dry Sliding Contact Against High Speed Steel, Surf. Coat. Technol., 1998, 108109, p 369-376

2. S Wilson and AT Alpas, Tribo-Layer Formation During Sliding Wear of TiN Coatings, Wear, 2000, 245, p 223-229

3. G Xu, Z Zhou, and J Liu, A Comparative Study on Fretting WearResistant Properties of Ion-Plated TiN and Magnetron-Sputtered $\mathrm{MoS}_{2}$ Coatings, Wear, 1999, 224, p 211-215

4. EE Vera, M Vite, R Lewis, EA Gallardo, and JR Laguna-Camacho, A Study of the Wear Performance of TiN, CrN and WC/C Coatings on Different Steel Substrates, Wear, 2011, 271, p 2116-2124

5. M Hua, HY Ma, J Li, and CK Mok, Tribological Behaviours of Patterned PVD TiN Spot Coatings on M2 Steel Coated with Different Bias Voltages, Surf. Coat. Technol., 2006, 200, p 3612-3625

6. J An and QY Zhang, Structure, Hardness and Tribological Properties of Nanolayered TiN/TaN Multilayer Coatings, Mater. Charact., 2007, 58, p 439-446 
7. S Zhang and X Zhang, Toughness Evaluation of Hard Coatings and Thin Films, Thin Solid Films, 2012, 520, p 2375-2389

8. DE Wolfe, J Singh, and K Narasimhan, Synthesis of Titanium Carbide/ Chromium Carbide Multilayers by the Co-Evaporation of Multiple Ingots by Electron Beam Physical Vapor Deposition, Surf. Coat. Technol., 2002, 160, p 206-218

9. GR Anstis, P Chantikul, BR Lawn, and DB Marshall, A Critical Evaluation of Indentation Techniques for Measuring Fracture Toughness: I Direct Crack Measurements, J. Am. Ceram. Soc., 1981, 64, p 533-538

10. W Shi, H Dong, and T Bell, Tribological Behaviour and Microscopic Wear Mechanisms of UHMWPE Sliding Against Thermal OxidationTreated Ti6A14V, Mater. Sci. Eng., 2000, A291, p 27-36

11. Y Yan, A Neville, D Dowson, and S Williams, Tribocorrosion in Implants-Assessing High Carbon and Low Carbon Co-Cr-Mo Alloys by In Situ Electrochemical Measurements, Tribol. Int., 2006, 39, p $1509-1517$
12. $\mathrm{J}$ Lin, $\mathrm{M}$ Liu, and JD Wu, Analysis of the Friction and Wear Mechanism of Structural Ceramic Coatings: Part 2: The Effect of Operating Conditions and Substrate Material, Wear, 1996, 198, p 7-14

13. C Cho and Y Lee, Effects of the Oxide Layer Formed on TiN Coated Silicon Wafer on the Friction and Wear Characteristics in Dry Sliding, Surf. Coat. Technol., 2003, 168, p 84-90

14. Q Wang, F Zhou, Z Zhou, Y Yang, C Yan, C Wang, and W Zhang, Influence of Carbon Content on the Microstructure and Tribological Properties of TiN(C) Coatings in Water Lubrication, Surf. Coat. Technol., 2012, 206, p 3777-3787

15. TE Fischer and $\mathrm{H}$ Tomizawa, Interaction of Tribochemistry and Microfracture in the Friction and Wear of Silicon Nitride, Wear, 1985, 105, p 29-45

16. Q Wang, F Zhou, K Chen, M Wang, and T Qian, Friction and Wear Properties of TiCN Coatings Sliding Against SiC and Steel Balls in Air and Water, Thin Solid Films, 2011, 519, p 4830-4841 